\title{
Do Age of Onset and Course of Illness Define Biologically Distinct Groups Within Atypical Depression?
}

\author{
Jonathan W. Stewart, Gerard E. Bruder, Patrick J. McGrath, and Frederic M. Quitkin \\ New York State Psychiatric Institute and Columbia University College of Physicians and Surgeons
}

\begin{abstract}
Illness course separates patients with atypical depression into tricyclic responders and nonresponders as does perceptual asymmetry. The authors therefore investigated whether the course-of-illness parameters would define groups within atypical depression differing in brain laterality. Patients with atypical depression were assessed for illness course and brain laterality. Two patient groups were defined, 1 with onset prior to age 20 plus a very chronic course, and a 2nd group having later onset or less chronic illness. Patients reporting early onset of very chronic dysphoria showed significantly less right-ear (lefthemisphere) accuracy and also differed in characteristic perceptual asymmetry when compared to patients with later onset or less chronicity. Course of illness may usefully define more homogeneous depressive subgroups within atypical depression.
\end{abstract}

Inclusion of atypical features as a modifier for major depression and dysthymia in the Diagnostic and Statistical Manual of Mental Disorders (DSM-IV; American Psychiatric Association, 1994) rested, in part, on inferior responsivity of atypical depression to tricyclic antidepressants relative to monoamine oxidase inhibitors (Rabkin et al., 1996). Because melancholia is a later onset (Nierenberg, Alpert, Pava, Rosenbaum, \& Fava, 1998; Parker, Roy, Hadzi-Pavlovic, Wilhelm, \& Mitchell, 2001; Stewart, McGrath, Rabkin, \& Quitkin, 1993) and less chronic disorder (Asnis, McGinn, \& Sanders, 1995; Stewart et al., 1993) relative to atypical depression, and is tricyclic-responsive (Bielski \& Friedel, 1976; Joyce \& Paykel, 1989), we investigated whether course-of-illness variables would differentiate within patients with atypical depression those who would be tricyclic-responsive from those whose mood would not benefit from tricyclic antidepressants. Stewart, McGrath, and Quitkin (2002) previously reported that patients with onset after age 20 or with a nonchronic course of illness responded to imipramine significantly more often than to placebo and no less often than to the monoamine oxidase inhibitor, phenelzine. In contrast, patients with early onset and a very chronic course of illness responded no more often to imipramine than to

Jonathan W. Stewart, Patrick J. McGrath, and Frederic M. Quitkin, Department of Therapeutics, New York State Psychiatric Institute, and Department of Psychiatry, Columbia University College of Physicians and Surgeons; Gerard E. Bruder, Department of Biopsychology, New York State Psychiatric Institute, and Department of Psychiatry, Columbia University College of Physicians and Surgeons.

This research was supported in part by National Institute of Mental Health grants MH 36295 and 56058, and a generous donation from Andrea Wilson. We thank Paul Leite, Barbara Stuart, and Nil Bhattacharya for assistance in data collection and analysis; Deborah Deliyannides and other members of the Depression Evaluation Service, where diagnostic evaluations of patients were conducted; and Freedom From Fear on Staten Island for help in patient recruitment.

Correspondence concerning this article should be addressed to Jonathan W. Stewart, 1051 Riverside Drive, New York, New York 10032. E-mail: jws6@columbia.edu placebo and significantly less often to imipramine than to phenelzine. This pharmacologic dissection (D. F. Klein, 1989) suggested that biological differences might exist within atypical depression and that age of onset and course of illness might help to define these differences.

Other work found that compared to patients with atypical depression, depressed patients with melancholic features demonstrated significantly poorer right-hemisphere processing on dichotic listening tests (Bruder et al., 1989). Further, whether they had atypical depression or not, depressed patients who responded to a tricyclic antidepressant differed from nonresponders in showing dichotic listening suggestive of poor right-hemisphere processing (Stewart, Quitkin, McGrath, \& Bruder, 1999). Although on average they may differ from patients with melancholia, patients with atypical depression appear to include some individuals who have similarities with melancholic patients, and others who differ from melancholic patients in terms of both biology and treatment outcome. Thus, atypical depression may define a heterogeneous mixture of patients having at least two different disorders, one with features similar to patients with melancholia, for example, later onset (Parker et al., 2001), less chronicity (Kendler et al., 1996), tricyclic responsivity (Bielski \& Friedel, 1976; Joyce \& Paykel, 1989), relative preference for left- over right-hemisphere processing (Bruder et al., 1989); and another with different clinical features and brain laterality, for example, early onset (Nierenberg et al., 1998; Stewart et al., 1993), chronic course of illness (Asnis et al., 1995; Stewart et al., 1993), poor tricyclic response (Stewart et al., 2002), and relative preference for right- over left-hemisphere processing (Bruder et al., 1989).

Here, we investigated a new group of patients with atypical depression who were not included in the preceding hypothesisgenerating reports. We predicted that dichotic listening measures would differ between the two groups of patients with atypical depression defined by the course-of-illness variables previously identified as differentiating imipramine response. Specifically, we predicted that the group defined by later onset (age 20 or older) or nonchronic course of illness (at least one episode of well-being lasting as long as 2 months since first significant dysphoria) would 
show relatively increased left-hemisphere bias for processing dichotic stimuli compared to patients with early onset (prior to age 20) of a very chronic illness (no 2-month depression-free episode since onset).

\section{Methods}

\section{Participants}

Dichotic listening testing was offered to a consecutive series of depressed outpatients entering treatment protocols at the Depression Evaluation Service, an outpatient research clinic at the New York State Psychiatric Institute. Testing was limited to those with essentially normal hearing, defined as less than $30 \mathrm{~dB}$ hearing loss at $500,1,000$, and 2,000 $\mathrm{Hz}$ and no ear difference greater than $10 \mathrm{~dB}$. The patients were all aged 18-65, physically healthy, and met $D S M-I V$ criteria for a depressive disorder as determined by experienced research psychiatrists using the Structured Clinical Interview for DSM-IV Axis I Disorders-Patient Edition (SCIDI/P; First, Spitzer, Gibbon \& Williams, 1996).

To avoid potential circularity, the patients with atypical depression presented in this report do not include any of the patients used to generate the hypothesis (Bruder et al., 1989; Liebowitz et al., 1988; Quitkin et al., 1988, 1989; Stewart et al., 1999, 2002). We included patients meeting full $D S M-I V$ criteria for atypical features, as well as patients with "probable" atypical depression, defined as otherwise meeting $D S M-I V$ criteria for atypical features except for having exactly one "B" criterion (i.e., hyperphagia, hypersomnia, leaden paralysis, rejection sensitivity) rather than the two or more required by $D S M-I V$. Several lines of evidence suggest similar findings for patients with probable atypical depression as for those who meet full DSM-IV atypical features criteria (Quitkin et al., 1988; Stewart et al., 1993, 2002). For ease of presentation, the combined group is labeled atypical depression.

A course-of-illness form (Stewart et al., 2002) was completed at the initial interview by the evaluating research psychiatrist. This form includes age of onset of first significant dysphoria (not necessarily first identifiable major depressive episode) and subsequent course of illness, including whether there had been a period of well-being lasting at least 2 months that could not be attributed to treatment. Well-being was operationalized as being free from significant dysphoric mood. First significant dysphoria was obtained by asking patients how old they were when they first felt significantly depressed, unhappy, blue, or down in the dumps for a significant period of time (i.e., more often than not for at least several weeks). Patients with atypical depression were then divided into two groups, as in Stewart et al. (2002). One group consisted of patients who had early onset of a very chronic depressive illness. Early onset was defined as first significant dysphoria occurring prior to age 20. Chronic depression was defined as a depressive illness lasting at least 2 years with no well-being lasting as long as 2 months since onset of first significant dysphoria. The second group included patients who reported either onset at or after age 20 or at least one 2-month episode of well-being not attributable to treatment. Mean duration of well-being in the later or less chronic group was $28 \pm 39$ months (range $=0-144$ months)

\section{Comparison Groups}

In order to give these findings perspective, these two groups of patients having atypical depression were compared with 86 healthy controls and 17 depressed patients with melancholic features. Healthy controls were recruited from among students, staff, and others who responded to ads and posters around the Columbia Presbyterian Medical Center. All were determined to be free from Axis I psychiatric disorder by interview using the Schedule for Affective Disorders and Schizophrenia (Endicott \& Spitzer, 1978), amended to make Diagnostic and Statistical Manual of Mental Disorders (DSM-III-R; American Psychiatric Association, 1987) diag- noses. Depressed patients with melancholic features were recruited from among patients applying to treatment studies at the same clinic. Many of the healthy controls and melancholic patients have been previously reported (e.g., Bruder et al., 1989, 2002; Stewart et al., 1999). All participants were 18 to 65 years old and physically healthy.

\section{Procedures}

All participants completed the self-rated Edinburgh Handedness Inventory (Oldfield, 1971). This instrument lists a variety of tasks and asks participants to indicate which hand they typically use for that task. A positive laterality quotient (LQ) score indicates an individual who tends to do more things with his or her right hand than with the left, whereas negative LQ scores are found in predominantly left-handed people. A fully right-handed individual would score +100 , whereas a completely lefthanded person would score -100 , and someone who is ambidextrous would have an LQ score near zero.

All procedures were approved by an Institutional Review Board, and all participants signed informed consent prior to any study procedures. All participants were drug-free at least 7 days prior to testing, although most, including all previously on fluoxetine, had been drug-free at least 1 month.

Dichotic listening testing. Participants were tested on consonantvowel syllable (CV) and complex tone (CT) tests, the order of which was alternated across participants (for details, see Bruder et al., 1989). The CV test (Berlin, Hughs, Lowe-Bell, \& Berlin, 1973) simultaneously presents a different nonsense syllable (e.g., $g a, b a$ ) to each ear. On an answer sheet containing six possible choices, the participant indicates which syllable was heard in each ear. Following practice, each participant receives 60 test trials. In normal adults, the $\mathrm{CV}$ test yields a mean right-ear advantage (Speaks, Niccum, \& Carney, 1982) reflecting superior processing of verbal information by the left parietotemporal cortex (Bruder, Kayser, et al., 1999; Coffey, Bryden, Schroering, Wilson, \& Mathew, 1989; Milner, Taylor, \& Sperry, 1968; Zaidel, 1983; Zatorre, Evans, Meyer, \& Gjedde, 1992).

The CT test (Sidtis, 1981) simultaneously presents a complex tone of different fundamental frequency to each ear. The participant reports whether a subsequent comparison tone is the same as one of the test tones, or different from both. Following practice, each participant receives 112 test trials in which half of the comparison tones match one of the dichotic pair (i.e., 28 for each ear), and half do not match either test tone. The CT test yields a mean left ear advantage in normal adults (Sidtis, 1981), presumably due to preferential processing of pitch information by the right parietotemporal cortex (Bruder, Kayser, et al., 1999; Coffey et al., 1989; Milner et al., 1968; Zaidel, 1983; Zatorre et al., 1992).

Scoring. Absolute accuracy in each ear was computed for each test from the number of accurate responses divided by the number of presentations times 100. A measure of relative ear advantage was also obtained for each test by computing a perceptual asymmetry score according to the following formula: perceptual asymmetry $=100 \times(R-L) /(R+L)$, where $R$ indicates right-ear accuracy and $L$ indicates left-ear accuracy. A measure of characteristic perceptual asymmetry (Levy, Heller, Banich, \& Burton, 1983a) was obtained by computing the Z-scores for each test's perceptual asymmetry score (using means and standard deviations for all participants) and then averaging these two $Z$-scores. Because characteristic perceptual asymmetry is derived from $Z$-scores, zero indicates the overall group mean, not lack of asymmetry.

Other measures. Patients were also evaluated on the 21-item Hamilton Rating Scale for Depression (HAM-D; Hamilton, 1960) and the chimeric faces test (Levy, Heller, Banich, \& Burton, 1983b). In addition, because anxiety has been suggested as being important in both atypical depression (Davidson, Miller, Turnbull, \& Sullivan, 1982; Posternak \& Zimmerman, 2002) and in measures of cerebral laterality (Heller \& Nitschke, 1998), we also obtained the Spielberger State-Trait Anxiety Inventory (STAI; Spielberger, Gorsuch, Lushene, Vagg, \& Jacobs, 1983).

Statistical analyses. Because our initial interest was in determining whether course of illness variables would differentiate groups within 
atypical depression who have differences in dichotic testing, analogous to the way course of illness had differentiated treatment response, the first analyses were between the two groups with atypical depression as defined by course of illness. Only if these groups differed on the dichotic tests were they then to be compared with the other two groups (i.e., healthy controls and melancholic patients), the latter contrasts being moot if the two atypical depression groups did not differ. Because data for four groups are presented, some might deem a four-group analysis the most appropriate first step in analyzing the data. However, because a four-group analysis would not directly test our two-group hypothesis, we rejected a four-group approach. We note, however, that four-group analyses showed a highly significant Group $\times$ Ear interaction for accuracy scores, $F(3,158)=5.96$, $p<.001$, and a highly significant group effect for characteristic perceptual asymmetry, $F(3,158)=5.70, p<.001$ (further details are available from Jonathan W. Stewart). Also, because differences between melancholic patients and healthy controls have been previously reported (Bruder et al., 1989, 2002), these are not repeated here.

Assessments of between-groups differences for demographics and illness variables utilized chi-square or $t$ tests, as appropriate. Any significant between-groups differences not considered definitional were entered into subsequent analyses as covariates. The main analyses used repeatedmeasures analysis of covariance (ANCOVA) to assess between-groups differences in dichotic listening scores. First, accuracy scores were analyzed. In these analyses, test (CV, CT) and ear (left, right) were the repeated-measures within-subjects variables, whereas diagnostic group (early onset and chronic; later onset or nonchronic) was a between-subjects variable. Next, univariate ANCOVA was performed comparing the characteristic perceptual asymmetry scores for early onset, chronic and later onset or nonchronic groups. To place these findings into perspective, these two ANCOVAs were repeated to compare each of these groups separately, first with healthy controls and then with patients having melancholia. Because age differed among groups, it was included as a covariate in all analyses of dichotic testing. All tests were two-tailed and an alpha level of .05 was used to assert significance.

\section{Results}

\section{Atypical Depression}

Group characteristics. The sample consisted of 91 depressed patients, including 59 with early onset, chronic atypical depression and 32 with later onset or nonchronic atypical depression. The later onset or nonchronic group included 20 with early onset, nonchronic illness, 3 having later onset chronic disorder, and 9 reporting later onset, nonchronic depression: 21 (66\%) with DSM-IV atypical features, and 11 (34\%) with probable atypical depression. The early onset, very chronically depressed group included 29 (49\%) who met criteria for $D S M-I V$ atypical features and $30(51 \%)$ with probable atypical depression [rates of probable and definite atypical depression comparing the two course-of-illness groups, corrected $\left.\chi^{2}(1)=1.66, n s\right]$. Inclusion of patients with probable atypical depression did not weaken the analyses. Also, we compared dichotic scores between the early onset, very chronic group and the 20 early onset, nonchronic patients, and separately against the 12 later onset patients, and found the same between-groups differences to be significant. We also compared the dichotic scores of the 20 early onset, nonchronic patients with the 12 later onset patients and found no significant between-groups differences (data available from Jonathan W. Stewart on request).

Table 1 gives the demographic and clinical characteristics of the two groups with atypical depression as well as for the two comparison groups. The two atypical depression groups did not differ significantly in gender, ethnicity, education, handedness, or severity of depression as measured by the HAM-D scale. The only significant difference was the somewhat older age of the patients with later onset or nonchronic atypical depression. Subsequent analyses therefore covaried for age, which did not correlate significantly with age of onset $(r=.09, n s)$. There was no significant difference in handedness (LQ score) between the early onset, chronic versus later onset, nonchronic groups, $t(89)=0.15, n s$. Seven $(12 \%)$ in the early onset, chronic group had LQ scores below zero, indicating left handedness; $5(16 \%)$ later onset or nonchronic patients had LQ scores below zero, corrected $\chi^{2}(1)=0.03, n s$. LQ was not a significant variable alone or in interaction in the analyses, nor did removal of those with LQ scores below zero alter which differences were significant.

Accuracy scores. A repeated-measures ANCOVA applied to the accuracy scores for the two atypical depression groups covarying for age yielded a significant Group $\times$ Ear interaction, $F(1$, $88)=11.94, p<.001$, and several significant age effects, presented in the following. Thus, there was a difference in accuracy between groups that was dependent on the ear of presentation, but not test. Mean right-ear accuracy was significantly greater for patients with later onset or less chronic illness than for patients with early onset of a very chronic illness (group), $F(1,88)=8.31$, $p<.01$, whereas the groups did not differ in left ear accuracy (group), $F(1,88)=0.76$, ns. As can be seen in Table 2, the difference in right-ear accuracy between groups was about $5 \%$ for both the $\mathrm{CV}$ and $\mathrm{CT}$ tests. Although between-groups significance was only achieved for the right ear, within the early onset, very chronic group, left-ear accuracy was numerically greater, and within the later onset, less chronic group, the right ear was numerically more accurate. Averaging across tests, the early onset, very chronic group showed about equal accuracy for right and left ears, $t(58)=1.19, p<.30$ (paired $t$ test), whereas the later onset, less chronic group showed over $10 \%$ better accuracy for the right ear, $t(31)=5.25, p<.001$ (paired $t$ test). Table 3 gives the significance testing for relevant comparisons of groups presented in Table 2.

Accuracy was significantly affected by age, $F(1,88)=13.60$, $p<.001$, and there was a significant Age $\times$ Test interaction, $F(1$, $88)=10.23, p<.01$, but no Age $\times$ Ear, $F(1,88)=.01, n s$, or Group $\times$ Age, $F(1,88)=.471, n s$, interaction. Age was significantly correlated with accuracy on the CT test $(r=-.37, p<$ $.001)$, but not on the CV test $(r=-.13, n s)$. In addition to age, test was also a significant main effect, $F(1,88)=59.12, p<.001$, due to significantly higher accuracy on the CT test relative to the $\mathrm{CV}$ test $(t=14.70, p<.001)$.

Characteristic perceptual asymmetry. Given the significant Ear $\times$ Group interaction, and lack of significant Test $\times$ Group and Test $\times$ Ear $\times$ Group interactions, a further examination of perceptual asymmetry differences averaging across tests seemed appropriate. We therefore calculated a characteristic perceptual asymmetry score for each participant by averaging the $Z$-scores of the perceptual asymmetries for the $\mathrm{CV}$ and CT tests, thereby providing a task-independent index of relative hemispheric bias (Levy et al., 1983a). Figure 1 shows each participant's characteristic perceptual asymmetry score, with means for healthy controls (C) and melancholic patients (M) shown by arrows. Patients with early onset and chronic course had a negative mean score $(M=$ $-0.22, S D=0.65$ ), indicating a favoring of the left ear (right 


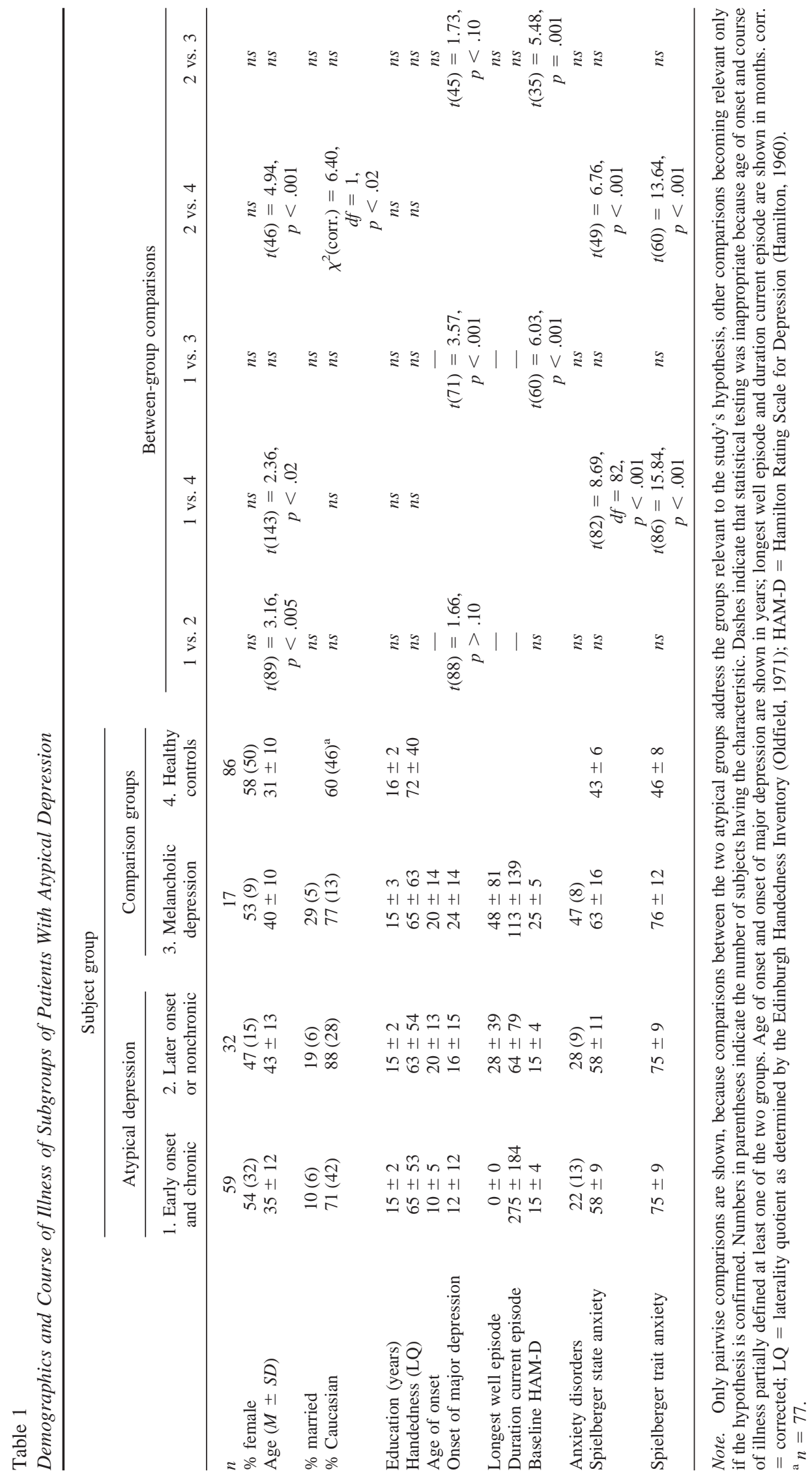


hemisphere) relative to the overall group mean. In contrast, patients with later onset or nonchronic course had a positive mean score $(M=0.28, S D=0.68)$, indicating a favoring of the right ear (left hemisphere) relative to the overall group mean. There was a significant difference in characteristic perceptual asymmetry scores between the two atypical groups, $F(1,88)=11.13, p<$ .001. Age was not a significant covariate, $F(1,88)=0.00, n s$.

\section{Comparisons With Healthy Controls}

To examine whether either atypical group might be considered abnormal, we compared each group to 86 healthy controls. A repeated-measures ANCOVA (covarying for age) of accuracy scores for healthy controls versus the patients with later onset or less chronic illness did not show group to be a significant variable alone or in interaction with other variables. By contrast, when this analysis was applied to healthy controls versus the early onset, chronic patients with atypical depression, there was a significant Ear $\times$ Group interaction, $F(1,141)=7.62, p<.01$. This interaction appears to be driven by a group difference in asymmetry rather than accuracy for either ear alone, as neither mean right-ear accuracy, $F(1,141)=0.96, n s$, nor mean left-ear accuracy, $F(1$, $141)=1.80, n s$, differed significantly between the healthy controls and the early onset, chronic patients. This relationship is supported by the significant difference in characteristic perceptual asymmetry scores between the early onset, chronic patients and the healthy controls, $F(1,151)=4.33, p<.05$. As can be seen in Figure 1, the early onset, chronic patients had a more negative score than the healthy controls, indicating a right-hemisphere bias relative to the healthy controls. Despite the lack of a significant finding for ear accuracy, there was a significant difference in characteristic perceptual asymmetry between patients with later onset or less chronic course and the healthy controls, $F(1,114)=3.99, p<.05$. These patients had a more positive mean score, indicative of a left-hemisphere bias relative to healthy controls.

\section{Comparisons With Melancholics}

A repeated-measures ANCOVA (covarying for age) of accuracy scores for patients with melancholia versus patients with early onset, chronic atypical depression yielded a significant Ear $\times$ Group interaction, $F(1,73)=13.30, p<.001$, and a significantly more negative mean characteristic perceptual asymmetry score, $F(1,73)=13.34, p<.001$; see Tables 2 and 3 . In contrast, neither of these analyses was significant in comparisons between patients with melancholia and those who had either later onset or less chronic atypical depression.

\section{Effect of Anxiety}

Comorbidity with anxiety disorders. It has been suggested that anxiety is common in atypical depression (Davidson et al., 1982). Although increased comorbid anxiety has been reported in atypical depression (Posternak \& Zimmerman, 2002), the importance of anxiety in atypical depression has not always been confirmed (e.g., Kendler et al., 1996; Quitkin et al., 1990), and DSM-IV did not include anxiety as a criterion for its atypical features modifier. Nevertheless, laterality differences have been reported between anxious and depressed individuals (Bruder, Wexler, Stewart, Price, 
Table 3

Statistics for Table 2

\begin{tabular}{|c|c|c|c|c|c|}
\hline Effect & 1 vs. 2 & 1 vs. 3 & 1 vs. 4 & 2 vs. 3 & 2 vs. 4 \\
\hline \multicolumn{6}{|c|}{ Accuracy scores (repeated-measures ANCOVA covarying for age) } \\
\hline Test & $\begin{array}{c}F(1,88)=59.12 \\
p<.001\end{array}$ & $\begin{array}{c}F(1,73)=20.89 \\
p<.001\end{array}$ & $\begin{array}{c}F(1,141)=61.25 \\
p<.001\end{array}$ & $\begin{array}{c}F(1,46)=7.64 \\
p<.01\end{array}$ & $\begin{array}{c}F(1,114)=38.63 \\
p<.001\end{array}$ \\
\hline Age & $\begin{array}{c}F(1,88)=13.60 \\
p<.001\end{array}$ & $\begin{array}{c}F(1,73)=6.26 \\
p<.02\end{array}$ & $\begin{array}{c}F(1,141)=12.08 \\
p<.001\end{array}$ & $\begin{array}{c}F(1,46)=11.60 \\
p<.005\end{array}$ & $\begin{array}{c}F(1,114)=15.63 \\
p<.001\end{array}$ \\
\hline Group & $\begin{array}{l}F(1,88)=1.78 \\
p<.20\end{array}$ & $\begin{array}{l}F(1,73)=.54 \\
\quad p<.50\end{array}$ & $\begin{array}{c}F(1,45)=.02 \\
\quad p<.90\end{array}$ & $\begin{array}{l}F(1,46)=3.56 \\
\quad p<.10\end{array}$ & $\begin{array}{l}F(1,114)=2.46 \\
\quad p<.20\end{array}$ \\
\hline Test $\times$ Group & $\begin{array}{l}F(1,88)=2.86 \\
\quad p<.10\end{array}$ & $\begin{array}{l}F(1,73)=.05 \\
\quad p<.90\end{array}$ & $\begin{array}{c}F(1,45)=.00 \\
\quad p<1.00\end{array}$ & $\begin{array}{c}F(1,46)=.26 \\
\quad p<.70\end{array}$ & $\begin{array}{l}F(1,114)=.93 \\
p<.40\end{array}$ \\
\hline Test $\times$ Age & $\begin{array}{c}F(1,88)=10.23 \\
p<.002\end{array}$ & $n s$ & $\begin{array}{c}F(1,141)=7.62 \\
p<.01\end{array}$ & $n s$ & $n s$ \\
\hline Ear $\times$ Group & $\begin{array}{c}F(1,88)=11.94 \\
p<.001\end{array}$ & $\begin{array}{c}F(1,73)=13.30 \\
p<.001\end{array}$ & $\begin{array}{l}F(1,141)=4.44 \\
\quad p<.05\end{array}$ & $\begin{array}{c}F(1,46)=1.6 \\
p<.30\end{array}$ & $\begin{array}{l}F(1,114)=1.56 \\
\quad p<.30\end{array}$ \\
\hline Test $\times$ Ear & $n s$ & $n s$ & $\begin{array}{c}F(1,141)=8.01 \\
p<.01\end{array}$ & $n s$ & $\begin{array}{c}F(1,114)=10.84 \\
p<.005\end{array}$ \\
\hline Ear $\times$ Age & $n s$ & $n s$ & $n s$ & $\begin{array}{c}F(1,46)=4.86 \\
p<.05\end{array}$ & $n s$ \\
\hline
\end{tabular}

Characteristic perceptual asymmetry

\begin{tabular}{|c|c|c|c|c|c|}
\hline oup & $\begin{array}{c}F(1,88)=11.13 \\
p<.002\end{array}$ & $\begin{array}{c}F(1,73)=13.34, \\
p<.001\end{array}$ & 41) $=4.33$, & $n$ & $14)=3.99$, \\
\hline
\end{tabular}

Note. All statistics involving group are shown, whether significant or not. Other statistics are reported only if significant. Only pairwise comparisons are shown, because comparisons between the two atypical groups address the groups relevant to the study's hypothesis, other comparisons becoming relevant only if the hypothesis is confirmed. Significant findings are in bold. ANCOVA $=$ analysis of covariance.

\& Quitkin, 1999; Heller \& Nitschke, 1998; Keller et al., 2000), so the question arises as to whether the preceding findings might be at least partly accounted for by comorbid anxiety. We assessed this possibility in two ways. First, we covaried for presence or absence of an anxiety disorder. Next, we covaried for level of anxiety as measured by the STAI. The percentage of patients having atypical depression with a comorbid anxiety disorder did not differ between those with early onset, chronic course $(22 \%)$ and those with later onset or nonchronic course $(28 \%)$, corrected $\chi^{2}(1)=0.15$, ns; neither did the STAI State Anxiety score $(58 \pm 9$ vs. $58 \pm 11)$ $t(84)=0.25, n s$, nor the STAI-Trait-Anxiety score $(75 \pm 9$ vs. $75 \pm 9), t(84)=0.36, n s$, differ between the groups. This suggests that comorbid anxiety disorder and levels of measured anxiety were independent of the groupings produced by the course-ofillness parameters. To examine further whether comorbid anxiety could have accounted for the group differences in dichotic accuracy and characteristic perceptual asymmetry, we reran the dichotic accuracy and characteristic perceptual asymmetry analyses including presence or absence of a comorbid anxiety disorder as a second grouping variable. In no case was anxiety disorder a significant main effect or interaction. Inclusion of the STAI scores as covariates also did not result in the loss of significance of the group effects or emergence of significant anxiety effects in these analyses (results available from Jonathan W. Stewart upon request).

Chimeric faces. A different laterality measure, the chimeric faces test (Levy et al., 1983b), has been shown to differ between depressed and anxious individuals (Heller \& Nitschke, 1998), as well as between patients having atypical and typical depressions (Bruder et al., 2002). In this test, participants were asked which of two emotional chimeric faces is happier. Each face is a composite picture consisting of either the left side smiling and the right side with a neutral expression, or vice versa. Negative scores indicate a left hemispatial bias, taken to reflect relatively increased righthemisphere processing, and positive scores indicate a right hemispatial bias, assumed to reflect increased left-hemisphere processing. The patients with atypical depression who reported early onset and a very chronic illness course had numerically more negative scores than those with either later onset or nonchronic course of illness, but this difference was not statistically significant $(-39 \pm 46$ vs. $-22 \pm 47), t(77)=1.57, n s$.

\section{Discussion}

These findings demonstrate that course-of-illness variables previously shown to differentiate treatment response within patients with atypical depression (Stewart et al., 2002) also apply to perceptual processing. For both treatment outcome and perceptual processing, age of onset of first dysphoria prior to age 20 and a very chronic course of illness defined a group of patients with atypical depression that differed significantly from diagnostically similar patients who had either later onset or a less chronic illness. The early onset, very chronic group responded more poorly to tricyclic antidepressants in the earlier study, and in the present study reported dichotic syllables or tones less accurately in the right ear (presumably reflecting poorer processing in the left hemisphere) when compared with those having either later onset or less chronic atypical depression. A task-independent measure of characteristic perceptual asymmetry supported the hypothesis that the later onset or nonchronic patients show a relative favoring of 


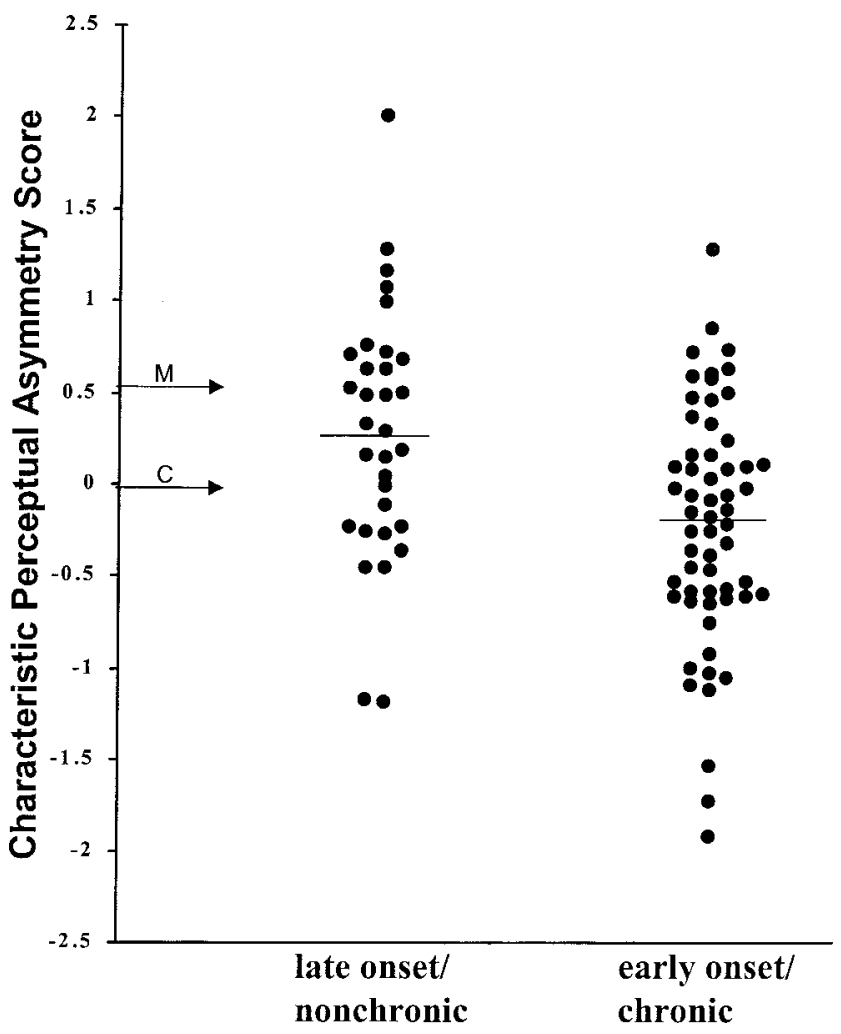

Figure 1. Characteristic perceptual asymmetry. Later onset/nonchronic indicates patients with atypical depression who reported first dysphoria at or after age 20 or who reported at least one episode of well-being lasting 2 months or longer subsequent to onset. Early onset/chronic indicates patients with atypical depression who reported onset of first dysphoria prior to age 20 and no well-being subsequently. Solid lines indicate group means. The arrow labeled $\mathrm{C}$ indicates the mean for 86 identically tested participants without identified psychiatric disorder, and the arrow labeled $\mathrm{M}$ indicates the mean of 17 identically tested depressed patients with melancholic features. Because characteristic perceptual asymmetry is derived from $Z$ scores, positive scores indicate increased left-hemisphere processing relative to the group mean, whereas negative scores indicate increased right-hemisphere processing relative to the group mean.

left- over right-hemisphere processing, whereas the early onset, very chronic patients tend to show the opposite bias. That both groups' perceptual asymmetry differed significantly from healthy controls, but in opposite directions, seems most consistent with the two groups having different abnormalities in perceptual processing, rather than lying on a continuum from normal to abnormal. Further, the later onset or nonchronic patients share course of illness (i.e., later onset, Parker et al., 2001; and less chronic course, Kendler et al., 1996), treatment response (i.e., relatively high likelihood of responding to tricyclic antidepressants: Bielski \& Friedel, 1976; Joyce \& Paykel, 1989), and perceptual asymmetry (i.e., relative favoring of left- over right-hemisphere auditory processing: Bruder et al., 1989, 2002) with melancholic patients, whereas the early onset, chronic atypical group differs from both melancholic patients and the later onset, nonchronic group on all of these dimensions. Thus, the later onset or nonchronic patients with atypical depression appear to have more in common with melan- cholic patients than with early onset, very chronic patients with atypical depression. This argues that the $D S M-I V$ criteria for atypical features may identify two populations of patients, one that is more similar to depressed patients with melancholic features, and one that differs from both groups and therefore may have a different illness.

Bruder et al. (1989) reported that differences between atypical and melancholic depression in perceptual asymmetry were attributable to differences in left-ear accuracy, which is indicative of a difference in right-hemisphere function. In the present study, differences in perceptual asymmetry between the early onset, very chronic patients with atypical depression and those with later onset or nonchronic depression were attributable to differences in rightear accuracy, which would point to a difference in left-hemisphere function. How can we reconcile these seemingly different findings? A common element in these findings is the tendency for depressed patients with melancholia and patients with late onset or nonchronic atypical depression to have a characteristic perceptual asymmetry favoring left- over right-hemisphere processing. Perhaps it is this difference in hemispheric bias that is important, rather than the absolute level of performance for items presented in either ear. This is supported by the difference in findings between the late onset or less chronic patients and healthy controls, where it was characteristic perceptual asymmetry that differentiated between these groups and not the accuracy level for either ear alone. Alternatively, the difference in absolute accuracy on each side may be critical. Although we argued above that patients with atypical depression who have a late onset or less chronic course are similar to patients with melancholia, they may in fact have a different illness with different lateralized hemispheric dysfunction when compared to both early onset, chronic patients with atypical depression and patients with melancholia. Further studies are needed to determine which of these possibilities pertain.

Independent of course of illness, age also correlated significantly with accuracy of dichotic listening. Coupled with the observation that the later onset, less chronically depressed patients were somewhat older, one might wonder whether the betweengroups dichotic listening differences might be better accounted for by age than by course of illness. This appears not to be the case, as covarying for age did not remove the between-groups differences, and age-related effects were task dependent, whereas group differences were not. Further, age was not a significant covariate in analyses of characteristic perceptual asymmetry. Finally, there were no age by group interactions, suggesting that the effect of age on dichotic scores was similar across the two groups. Thus, although important in general, age did not appear to account for the between-groups differences found for ear accuracy.

Anxiety has been proposed to indicate relatively increased righthemisphere processing, whereas depression has been associated with the opposite hemispheric asymmetry (Heller \& Nitschke, 1998; Keller et al., 2000), and increased anxiety has been suggested for patients with atypical depression (Davidson et al., 1982; Posternak \& Zimmerman, 2002). Might the decreased right-ear accuracy shown by the early onset, very chronic patients with atypical depression be accounted for by anxiety-related favoring of right-hemisphere processing? Apparently this was not the case, as the two groups of patients with atypical depression did not differ in rates of comorbid anxiety disorders or in levels of anxiety as measured by the STAI. Also, inclusion of comorbid anxiety or 
STAI scores did not alter the findings, nor were they significant as main effects or covariates, or in interactions with other variables.

How can we explain, then, the earlier finding of differences between depressed patients with and without anxiety disorders (Bruder, Wexler, et al., 1999) and the lack of an anxiety effect reported here? One possibility is that presence or absence of comorbid anxiety disorders does not affect patients with atypical depression in the same way as it affects other depressed patients. Another is that Bruder, Wexler, et al. included a different verbal task (i.e., the fused rhymed words test; Wexler \& Halwes, 1983) than the CV test used here. Although the perceptual asymmetry score on the fused rhymed word test correlated significantly with the perceptual asymmetry for the CV test $(r=.41, p<.001)$ in patients with atypical depression, the correlation accounts for only about $17 \%$ of the variance. Hence, the CV and fused rhymed word tests may provide largely different information, as may also be true for the chimeric faces test (correlation with CV test, $r=.01, n s$ ). This agrees with Kim and Levine (1992), who argued that the concept of characteristic perceptual asymmetry may not apply well across all laterality tests, particularly those in a different modality (e.g., visual vs. aural).

Age of onset, chronicity, and depression have been investigated previously, although infrequently specifically addressing atypical depression. Early onset of major depression, for example, predicts increased likelihood of recurrence (Kessing, 1998) and early onset dysthymia is correlated with longer episodes of major depression and increased comorbidity with personality disorders and substance use disorders (D. N. Klein et al., 1999). Additionally, early onset of major depression predicts chronicity (Benazzi, 2000; Hoencamp, Haffmans, Griens, Huijbrechts, \& Heycop ten Ham, 2001) and D. N. Klein, Schwartz, Rose, and Leader (2000) showed dysthymia to be a pernicious illness, unlikely to remit over 5 years, highly likely to relapse if remitted, and with increased overall symptomatology, suicide attempts and hospitalizations, and decreased overall functioning relative to recurrent major depression. Further, early onset of a depressive disorder may be familial (Wickramaratne \& Weissman, 1998). Two reports compared patients having atypical depression with other patients. Nierenberg et al. (1998) reported that, compared with depressed patients with melancholic features, patients with atypical depression had earlier age of onset and increased rates of personality disorder, bulimia, and body-dysmorphic disorder. Posternak and Zimmerman (2002) also reported earlier onset, as well as a more chronic course of illness in patients with atypical depression compared with other patients with major depression. Thus, there is some consensus that earlier onset of depression is associated with a more pernicious illness in terms of comorbidity, psychosocial functioning, and a more chronic course of illness, and that atypical depression may be an early onset, chronic disorder. However, whether these findings are specific to atypical depression, or just more likely in atypical depression remains to be determined. Further, none of these studies reported biologic or physiologic correlates.

The only literature we are aware of linking atypical depression, age of onset, and a biological finding are two studies of different brain measures in the same group of patients. Fotiou, Fountoulakis, Iacovides, and Kaprinis (in press) report shortened event-related potentials in patients with atypical depression relative to patients with melancholia, and a significant positive correlation between event-related potentials and age of onset of depressive illness.
These same patients (Fountoulakis et al., 2002) also demonstrated increased blood flow in the right frontal lobes. Blood flow also correlated negatively with age of onset, although in different brain regions (left temporal lobe and left globus pallidus). Together, these findings corroborate different biology in atypical and melancholic depressions, and the importance of age of onset in this biology.

A limitation of this study is that memory is notoriously faulty. We have no independent confirmation, for example, as to whether patients who reported early onset or lack of significant subsequent well-being actually had that history, although others have reported good test-retest reliability of reports of both age of onset (Farrer, Florio, Bruce, Leaf, \& Weissman, 1989; D. N. Klein et al., 1998; Prusoff, Merikangas, \& Weissman, 1988) and chronicity (D. N. Klein et al., 1998). Those who claimed an episodic course may have been mildly depressed between episodes, or perhaps some patients reported their entire lives as having been dreary, when they actually experienced depression-free episodes. Such reporting errors would serve to blur between-group distinctions, so do not undermine the reported differences. However, they do raise questions about potential replication, and about potential application to individual patients. For example, we have not found onset of major depression to be a good discriminator in either this sample (data available from Jonathan W. Stewart upon request) or a previous one (Stewart et al., 2002), and so the usual method of charting episodes of major depression might not adequately distinguish within atypical depression. Some patients, for example, will describe what sounds like a clearly episodic course of illness, but when more carefully questioned, acknowledge that even between seemingly discrete episodes, they were depressed, albeit more mildly. Failure to question patients carefully about their emotional state between episodes could result in inappropriate categorization, at least according to the system used here.

Judd and Akiskal (2000) have conceptualized depression as a single illness of varying severity, arguing that distinctions among major depression, dysthymia, and subsyndromal depression are artificial. Our findings agree that the major depression, dysthymia, and subsyndromal distinctions may not be meaningful, but also argue that depression may include meaningfully distinct entities, including atypical depression and melancholia.

If confirmed by additional biologic, treatment, longitudinal course and family-genetic studies, the results suggest that atypical depression may include patients having at least two distinct disorders. One disorder is characterized by early onset, a very chronic course of dysphoria, increased right-hemisphere bias on dichotic listening tests, and specific monoamine oxidase inhibitor response relative to tricyclic antidepressants. A second disorder has a later age of onset, a less chronic course of illness, dichotic testing consistent with a relative left-hemisphere bias, and robust tricyclic response. The similarities between the later onset or less chronic patients with atypical depression and patients with melancholia, taken together with differences between both of these groups and those with early onset, very chronic atypical depression, suggest that the latter group does not belong diagnostically with the later onset or nonchronic group. Therefore, $D S M-V$ might consider adding criteria to its atypical features modifier requiring that onset of first dysphoria be prior to age 20 without a spontaneous remission lasting as long as 2 months since onset. 


\section{References}

American Psychiatric Association. (1987). Diagnostic and statistical manual of mental disorders (3rd ed., rev.). Washington, DC: Author.

American Psychiatric Association. (1994). Diagnostic and statistical manual of mental disorders (4th ed.). Washington, DC: Author.

Asnis, G., McGinn, L., \& Sanders, W. (1995). Atypical depression: Clinical aspects and noradrenergic function. American Journal of Psychiatry, $152,31-36$

Benazzi, F. (2000). Early-onset versus late-onset atypical depression: Unipolar and bipolar II. Journal of Affective Disorders, 61, 95-99.

Berlin, C. I., Hughs, L. F., Lowe-Bell, S. S., \& Berlin, H. L. (1973). Dichotic right-ear advantage in children 5 to 13. Cortex, 9, 394-402.

Bielski, R. J., \& Friedel, R. O. (1976). Prediction of tricyclic antidepressant response: A critical review. Archives of General Psychiatry, 33, 14791489.

Bruder, G. E., Kayser, J., Tenke, C., Amador, X., Friedman, M., Sharif, Z., \& Gorman, J. (1999). Left temporal lobe dysfunction in schizophrenia: Event-related potential and behavioral evidence from phonetic and tonal dichotic listening tasks. Archives of General Psychiatry, 56, 267-276.

Bruder, G. E., Quitkin, F. M., Stewart, J. W., Martin, C., Voglmaier, M. M., \& Harrison, W. M. (1989). Cerebral laterality and depression: Differences in perceptual asymmetry among diagnostic subtypes. Journal of Abnormal Psychology, 98, 177-186.

Bruder, G. E., Stewart, J. W., McGrath, P. J., Ma, J. G., Wexler, B. E., \& Quitkin, F. M. (2002). Atypical depression: Enhanced right hemispheric dominance for perceiving emotional chimeric faces. Journal of Abnormal Psychology, 111, 446-454.

Bruder, G. E., Wexler, B. E., Stewart, J. W., Price, L. H., \& Quitkin, F. M. (1999). Perceptual asymmetry differences between major depression with or without a comorbid anxiety disorder: A dichotic listening study. Journal of Abnormal Psychology, 108, 233-239.

Coffey, C. E., Bryden, M. P., Schroering, E. S., Wilson, W. H., \& Mathew, R. J. (1989). Regional cerebral blood flow correlates of a dichotic listening task. Journal of Neuropsychiatry, 1, 46-52.

Davidson, J. R., Miller, R. D., Turnbull, C. D., \& Sullivan, J. L. (1982). Atypical depression. Archives of General Psychiatry, 39, 527-534.

Endicott, J., \& Spitzer, R. L. (1978). A diagnostic interview: The schedule for affective disorders and schizophrenia. Archives of General Psychiatry, 35, 837-844.

Farrer, L. A., Florio, L. P., Bruce, M. L., Leaf, P. J., \& Weissman, M. M. (1989). Reliability of self-reported age at onset of major depression. Journal of Psychiatric Research, 23, 35-47.

First, M. B., Spitzer, R. L., Gibbon, M., \& Williams, J. B. W. (1996). Structured Clinical Interview for DSM-IV Axis 1 Disorders-Patient Edition (SCID-I/P, Version 2.0). (Available from the Biometrics Research Department, New York State Psychiatric Institute, 722 West 168th Street, New York, New York 10032)

Fotiou, F., Fountoulakis, K. N., Iacovides, A., \& Kaprinis, G. (in press). Pattern-reversed visual evoked potentials in subtypes of major depression. Psychiatry Research.

Fountoulakis, K. N., Iacovides, A., Gerasimou, G., Fotiou, F., Iannidou, C., Bascialla, F., et al. (2002). The relationship of regional cerebral blood flow with subtypes of major depression. World Journal of Biological Psychiatry, 2, 142S.

Hamilton, M. (1960). A rating scale for depression. Journal of Neurology, Neurosurgery and Psychiatry, 23, 56-62.

Heller, W., \& Nitschke, J. B. (1998). The puzzle of regional brain activity in depression and anxiety: The importance of subtypes and comorbidity. Cognition and Emotion, 12, 421-447.

Hoencamp, E., Haffmans, P. M., Griens, A. M., Huijbrechts, I. P., \& Heycop ten Ham, B. F. (2001). A 3.5-year naturalistic follow-up study of depressed outpatients. Journal of Affective Disorders, 66, 267-271.

Joyce, P. R., \& Paykel, E. S. (1989). Predictors of drug response in depression. Archives of General Psychiatry, 46, 89-99.
Judd, L. L., \& Akiskal, H. S. (2000). Delineating the longitudinal structure of depressive illness: Beyond clinical subtypes and duration thresholds. Pharmacopsychiatry, 33, 3-7.

Keller, J., Bhargava, T., Gergen, J. A., Miller, G. A., Nitschke, J. B., Deldin, P. J., \& Heller, W. (2000). Neuropsychological differentiation of depression and anxiety. Journal of Abnormal Psychology, 109, 3-10.

Kendler, K. S., Eaves, L. J., Walters, E. E., Neale, M. C., Heath, A. C., \& Kessler, R. C. (1996). The identification and validation of distinct depressive syndromes in a population-based sample of female twins. Archives of General Psychiatry, 53, 391-399.

Kessing, L. V. (1998). Recurrence in affective disorder: II. Effect of age and gender. British Journal of Psychiatry, 172, 29-34.

Kim, H., \& Levine, S. C. (1992). Variations in characteristic perceptual asymmetry: Modality specific and modality general components. Brain \& Cognition, 19, 21-47.

Klein, D. F. (1989). The pharmacological validation of psychiatric diagnosis. In L. Robins \& J. Barrett (Eds.), Validity of psychiatric diagnosis (pp. 203-216). New York: Raven.

Klein, D. N., Norden, K. A., Ferro, T., Leader, J. B., Kasch, K. L., Klein, L. M., et al. (1998). Thirty-month naturalistic follow-up study of earlyonset dysthymic disorder: Course, diagnostic stability, and prediction of outcome. Journal of Abnormal Psychology, 107, 338-348.

Klein, D. N., Schatzberg, A. F., McCullough, J. P., Keller, M. B., Dowling, F., Goodman, D., et al. (1999). Early- versus late-onset dysthymic disorder: Comparison in outpatients with superimposed major depressive episodes. Journal of Affective Disorders, 52, 187-196.

Klein, D. N., Schwartz, J. E., Rose, S., \& Leader, J. B. (2000). Five-year course and outcome of dysthymic disorder: A prospective, naturalistic follow-up study. American Journal of Psychiatry, 157, 931-939.

Levy, J., Heller, W., Banich, M. T., \& Burton, L. A. (1983a). Are variations among right-handed individuals in perceptual asymmetries caused by characteristic arousal differences between hemispheres? Journal of Experimental Psychology, 9, 329-359.

Levy, J., Heller, W., Banich, M. T., \& Burton, L. A. (1983b). Asymmetry of perception in free viewing of chimeric faces. Brain and Cognition, 2, 404-419.

Liebowitz, M. R., Quitkin, F. M., Stewart, J. W., McGrath, P. J., Harrison, W. M., Markowitz, J. S., et al. (1988). Antidepressant specificity in atypical depression. Archives of General Psychiatry, 45, 129-137.

Milner, B., Taylor, L. B., \& Sperry, R. W. (1968). Lateralized suppression and dichotically presented digits after commissural section in man. Science, 161, 184-185.

Nierenberg, A. A., Alpert, J. E., Pava, J., Rosenbaum, J. F., \& Fava, M. (1998). Course and treatment of atypical depression. Journal of Clinical Psychiatry, 59 (Suppl. 18), 5-9.

Oldfield, R. C. (1971). The assessment and analysis of handedness: The Edinburgh Inventory. Neuropsychologia, 9, 97-113.

Parker, G., Roy, K., Hadzi-Pavlovic, D., Wilhelm, K., \& Mitchell P. (2001). The differential impact of age on the phenomenology of melancholia. Psychological Medicine, 31, 1231-1236.

Posternak, M. A., \& Zimmerman, M. (2002). Partial validation of the atypical features subtype of major depressive disorder. Archives of General Psychiatry, 59, 70-76.

Prusoff, B. A., Merikangas, K. R., \& Weissman, M. M. (1988). Lifetime prevalence and age of onset of psychiatric disorders: Recall 4 years later. Journal of Psychiatric Research, 22, 107-117.

Quitkin, F. M., McGrath, P. J., Stewart, J. W., Harrison, W., Tricamo, E., Wager, S. G., et al. (1990). Atypical depression, panic attacks, and response to imipramine and phenelzine: A replication. Archives of General Psychiatry, 47, 935-941.

Quitkin, F. M., Stewart, J. W., McGrath, P. J., Liebowitz, M. R., Harrison, W. M., Tricamo, E., et al. (1988). Phenelzine versus imipramine in the treatment of probable atypical depression: Defining syndrome bound- 
aries of selective MAOI responders. American Journal of Psychiatry, $145,306-311$.

Rabkin, J. G., Stewart, J. W., Quitkin, F. M., McGrath, P. J., Harrison, W. M., \& Klein, D. F. (1996). Should atypical depression be included in $D S M-I V$ ? In T. A. Widiger, A. J. Frances, H. A. Pincus, R. Ross, M. B. First, \& W. W. Davis (Eds.), DSM-IV Sourcebook (Vol. 2, pp. 239260). Washington, DC: American Psychiatric Association.

Sidtis, J. J. (1981). The complex tone test: Implications for the assessment of auditory laterality effects. Neuropsychologia, 19, 103-112.

Speaks, C., Niccum, N., \& Carney, E. (1982). Statistical properties of responses to dichotic listening with $\mathrm{CV}$ nonsense syllables. Journal of the Acoustical Society of America, 72, 1185-1194.

Spielberger, C. D., Gorsuch, R. L., Lushene, R., Vagg, P. R., \& Jacobs, G. A. (1983). Manual for the State-Trait Anxiety Inventory. Palo Alto, CA: Consulting Psychologists Press.

Stewart, J. W., McGrath, P. J., \& Quitkin, F. M. (2002). Are age of onset and course of illness important determinants of atypical depression? Neuropsychopharmacology, 26, 237-245.

Stewart, J. W., McGrath, P. J., Rabkin, J. G., \& Quitkin, F. M. (1993). Atypical depression: A valid clinical entity? Psychiatric Clinics of North America, 16, 479-495.
Stewart, J. W., Quitkin, F. M., McGrath, P. J., \& Bruder, G. E. (1999). Do tricyclic responders have different brain laterality? Journal of Abnormal Psychology, 108, 707-710.

Wexler, B. E., \& Halwes, T. (1983). Increasing the power of dichotic methods: The fused rhymed words test. Neuropsychologia, 21, 59-66.

Wickramaratne, P. J., \& Weissman, M. M. (1998). Onset of psychopathology in offspring by developmental phase and parental depression. Journal of the American Academy of Child \& Adolescent Psychiatry, 37, 933-942.

Zaidel, E. (1983). Disconnection syndrome as a model for laterality effects in the normal brain. In J. B. Hellige (Ed.), Cerebral hemisphere asymmetry: Method, theory and application (pp. 95-151). New York: Praeger.

Zatorre, R. J., Evans, A. C., Meyer, E., \& Gjedde, A. (1992). Lateralization of phonetic and pitch discrimination in speech processing. Science, 256, 846-849.

Received January 25, 2002

Revision received August 20, 2002

Accepted August 27, 2002

\section{Members of Underrepresented Groups: Reviewers for Journal Manuscripts Wanted}

If you are interested in reviewing manuscripts for APA journals, the APA Publications and Communications Board would like to invite your participation. Manuscript reviewers are vital to the publications process. As a reviewer, you would gain valuable experience in publishing. The $\mathrm{P} \& \mathrm{C}$ Board is particularly interested in encouraging members of underrepresented groups to participate more in this process.

If you are interested in reviewing manuscripts, please write to Demarie Jackson at the address below. Please note the following important points:

- To be selected as a reviewer, you must have published articles in peer-reviewed journals. The experience of publishing provides a reviewer with the basis for preparing a thorough, objective review.

- To be selected, it is critical to be a regular reader of the five to six empirical journals that are most central to the area or journal for which you would like to review. Current knowledge of recently published research provides a reviewer with the knowledge base to evaluate a new submission within the context of existing research.

- To select the appropriate reviewers for each manuscript, the editor needs detailed information. Please include with your letter your vita. In your letter, please identify which APA journal(s) you are interested in, and describe your area of expertise. Be as specific as possible. For example, "social psychology" is not sufficient-you would need to specify "social cognition" or "attitude change" as well.

- Reviewing a manuscript takes time ( $1-4$ hours per manuscript reviewed). If you are selected to review a manuscript, be prepared to invest the necessary time to evaluate the manuscript thoroughly.

Write to Demarie Jackson, Journals Office, American Psychological Association, 750 First Street, NE, Washington, DC 20002-4242. 